Article

\title{
Time-Dependent Anisotropic Wetting Behavior of Deterministic Structures of Different Strut Widths on Ti6A14V
}

\author{
Georg Schnell ${ }^{1, *}$, Christopher Jagow ${ }^{1}$, Armin Springer ${ }^{2}$, Marcus Frank ${ }^{2,3}$ (]) \\ and Hermann Seitz ${ }^{1,3}$ (D) \\ 1 Microfluidics, Faculty of Mechanical Engineering and Marine Technology, University of Rostock, \\ Justus-von-Liebig Weg 6, 18059 Rostock, Germany \\ 2 Medical Biology and Electron Microscopy Centre, Medical Faculty, University of Rostock, Strempelstr. 14, \\ 18057 Rostock, Germany \\ 3 Deptartment Life, Light \& Matter, University of Rostock, Albert-Einstein-Str. 25, 18059 Rostock, Germany \\ * Correspondence: georg.schnell@uni-rostock.de; Tel.: +49-381-498-9093
}

Received: 11 July 2019; Accepted: 24 August 2019; Published: 27 August 2019

\begin{abstract}
This study investigated the wetting behavior of Ti6Al4V surfaces that were groove-structured by means of femtosecond laser irradiation. The material was treated under ambient air conditions by use of a laser wavelength of $1030 \mathrm{~nm}$ and a pulse duration of $300 \mathrm{fs}$. Highly accurate structures with a gap width of $20 \mu \mathrm{m}$, a gap depth of $10 \mu \mathrm{m}$, and varying strut widths $(1-300 \mu \mathrm{m})$ were generated and the contact angles in parallel and perpendicular direction were determined using sessile drop method with ultrapure water 1, 8, and 15 days after irradiation. All deterministic surfaces exhibited a pronounced contact angle change over time. The structures showed a strong anisotropic wetting behavior with a maximum contact angle aspect ratio of 2.47 at a strut width of $40 \mu \mathrm{m}$ and a maximum difference between the parallel and perpendicular contact angle of $47.9^{\circ}$ after 1 day.
\end{abstract}

Keywords: femtosecond laser; anisotropic wetting; Ti6Al4V; hydrophobic; hydrophilic; surfaces

\section{Introduction}

Nature makes use of the effect of anisotropic wetting of surfaces, as seen in rice leaves [1] or insect wings [2]. For instance, the stripe-textured butterfly wings provide a directional bias to control the resistance of motion of a droplet as it rolls off a surface. Derived from nature, this surface property is of great interest for technical applications. Potential applications include solar collectors, microreactor systems, microfluidics, membranes, lab-on-chip systems, and biosensing [3]. For such applications, the structuring of surfaces with a laser, specifically a femtosecond laser, is of particular significance. Due to the ability for creating stochastic (nano and/or micro) and highly precise deterministic structures, it is possible to initiate a desired wetting state in a rapid processing time. Additionally, the light absorption increases, which makes the technology especially useful for solar collectors [4-6]. Furthermore, the surface of solar collectors and sensors can be functionalized in a manner where water not only drips off, but also carries dust and dirt particles with it, which emphasizes the usefulness of bionic principles in technical applications.

The anisotropic wetting behavior of a surface is characterized by varying contact angles (CAs) in different directions. This behavior is often explained by an energy barrier to the movement of the contact line of the droplet due to (groove) structures [7]. This distortion causes considerable, direction-dependent deviations between the contact angles and the formation of rectangular or square-like bases of the drops. These phenomena have been considered in numerous studies, e.g., one-dimensional groove structures have already been investigated. Variations of these structures 
include process-related, almost-rectangular edges and a few pillar widths on coated structures [8]. Silicon micro-hoodoo structures were fabricated to study partial wetting on deterministic structures [9]. Hydrophilic structures with constant strut widths $(100 \mu \mathrm{m})$ and varying gap widths (hydrophobic) were applied onto a Pyrex glass substrate [10]. Quadratic shapes were manufactured, and the advancing and receding contact angles were examined [11]. Further investigations use chemical fabrication or surface coating methods to modify the wetting behavior of the surfaces. On microstructured surfaces modified with polymer brushes, it was demonstrated that the surface topography and the surface chemistry have a strong influence on the anisotropic behavior, while intermediate CAs lead to the highest drop shape anisotropy [12]. Due to process-related limitations, most studies were not able to investigate the entire range of strut widths as examined in the present study. The anisotropy of the wetting behavior on structures that have not been chemically modified has already been investigated. These microgrooved Si surfaces featured a fixed aspect ratio due to the manufacturing process, few strut width variations, and much deeper structures and therefore also wider trenches [13] compared to the present study.

Laser structuring with femtosecond lasers has rarely been used to investigate the contact angles on deterministic groove structures or grid structures. Superhydrophobic structures were applied between smooth surfaces and anisotropic droplet shapes were induced, but no trenches were created [14]. The influence of femtosecond laser radiation on groove and lattice structures was presented in a work for a few strut widths [15], but no anisotropic droplet formation was displayed. Moreover, it is known that laser structured metallic surfaces show a strong dependency on the wetting behavior with regard to time and ambient atmosphere [16-18].

The present study focuses on the wetting behavior of Ti6Al4V surfaces that were groove-structured by means of femtosecond laser irradiation. The time-dependent anisotropic wetting behavior of the deterministic structured surface was studied. The grooves featured a fixed geometry with both a constant gap width and gap depth, whereas the remaining strut width was varied across a broad range. The resulting contact angles and their time dependency were thoroughly analyzed regarding the impact of the geometrical parameters of the deterministic structure as well in terms of the change of the surface chemistry due to the laser machining.

\section{Materials and Methods}

\subsection{Materials}

The experimental investigations were carried out with Ti6Al4V samples $(1 \times 1 \times 0.4 \mathrm{~cm})$. The plates were purchased from S + D Spezialstahl Handelsgesellschaft mbH, Stelle, Germany, and the specifications of the material complies with the requirements of AMS4911 and WL 3.7164 Part 1. In order to ensure uniform surfaces with a low roughness, the samples were polished with silicon carbide abrasive sandpaper from P320 (t1 = $4 \mathrm{~min})$, P600 ( $2=4 \mathrm{~min})$, and P1200 ( 3 3 = $8 \mathrm{~min})$ grain sizes, leading to an average area surface roughness Sa of approximately $0.04 \mu \mathrm{m}$. Afterwards, the specimens were cleaned in an ultrasonic bath with ultrapure water for $5 \mathrm{~min}$. Drying was performed with dust-free wipes and compressed air.

\subsection{Laser Processing}

For laser structuring, a femtosecond fiber laser with an amorphous glass $\mathrm{Yb}$-doped core of the type UFFL_SHG from Active Fiber Systems GmbH, Jena, Germany, was used. The applied wavelength was $1030 \mathrm{~nm}$ with a pulse duration of $300 \mathrm{fs}$. The laser beam was deflected by a scanner system of the type intelliSCANse from the manufacturer Scanlab GmbH, Puchheim, Germany. The beam was focused by an F-theta lens with a focal length of $163 \mathrm{~mm}$, resulting in a theoretical beam diameter of 36 microns. The system enabled a repetition rate ranging from $50.3 \mathrm{kHz}$ up to $18.6 \mathrm{MHz}$, with an average power of up to $60 \mathrm{~W}$. The laser system is integrated in a five-axis micromachine center Microgantry GU4 (Kugler $\mathrm{GmbH}$, Salem, Germany). 
The structuring of all specimens took place on an area of $10 \mathrm{~mm} \times 10 \mathrm{~mm}$. The deterministic microstructures consisted of a parallel groove pattern with different strut widths. The structure parameters are illustrated in Figure 1. The relevant geometrical parameters were the gap depth (1), the gap width (2), and the strut width (3). Different surfaces were investigated with a strut width of $1,5,10,20,40,60,80,100,140,180,220,260$, and $300 \mu \mathrm{m}$ at a constant gap depth of $10 \mu \mathrm{m}$ and gap width of $20 \mu \mathrm{m}$. The aspect ratio of the trenches was selected according to the study of Martínez-Calderon et. al. [15] for comparison. In order to apply the microstructures to the Ti6Al4 samples, the influence of the pulse energy, the number of scan-repetitions, and the pulse overlap on the trench width and depth was investigated first. When selecting the laser parameters, special attention was paid to visible traces of melting and other undesirable phenomena (surface debris, recast layers, burrs) that could affect the results in the later contact angle study. The final laser scanning parameters are shown in Table 1.

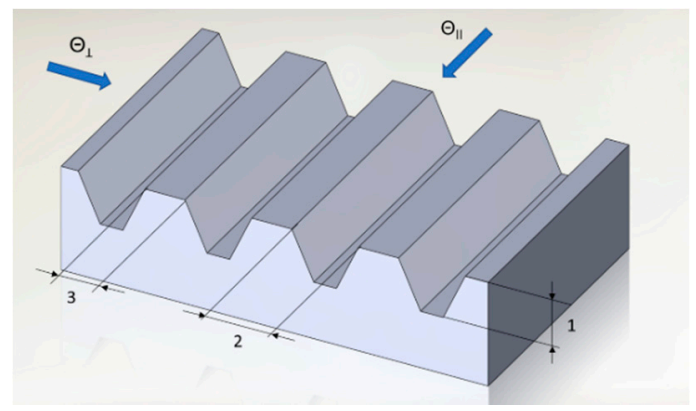

Figure 1. Simplistic illustration of the structure parameters and consideration of the contact angle measurement $\left(1\right.$ = gap depth, 2 = gap width, and 3 = strut width, as well as contact angle parallel $\Theta_{\|}$ and perpendicular $\Theta_{\perp}$ to the groove direction).

Table 1. Final laser parameter settings for processing of groove-structured surfaces with gap width of $20 \mu \mathrm{m}$ and gap depth of $10 \mu \mathrm{m}$.

\begin{tabular}{lc}
\hline \multicolumn{2}{c}{ Final Laser Parameter Settings } \\
\hline Pulse energy $(\mu \mathrm{J})$ & 7 \\
Fluence in focus $\left(\mathrm{J} / \mathrm{cm}^{2}\right)$ & 1.37 \\
Line overlap $(\%)$ & 50 \\
Number of overscans $(-)$ & 310 \\
\hline
\end{tabular}

\subsection{Surface Characterization and Investigation of Wetting Properties}

For the characterization of the surface structures, a confocal laser scanning microscope (CLSM) LEXT OLS 4000 and the software OLS4000 (Version 2.2.3, Olympus, Hamburg, Germany) were used. Optical magnifications of $50 \times$ and $100 \times$ were utilized, leading to scan areas of $256 \mu \mathrm{m} \times 256 \mu \mathrm{m}$ and $128 \mu \mathrm{m} \times 128 \mu \mathrm{m}$, respectively. For detailed images of the laser irradiated surfaces, a scanning electron microscope (SEM) Merlin VP compact (Carl Zeiss AG, Jena, Germany) was used. Energy dispersive X-ray spectroscopy (EDX) by means of Detector XFlash 6/30, Co. (Bruker, Berlin, Germany) was used to qualitatively determine the proportion of the chemical elements on the surfaces. The resulting contact angles of the structured and reference surfaces were measured 1, 8, and 15 days after laser treatment with the OCA 40 Micro (DataPhysics Instruments GmbH, Filderstadt, Germany). Measures of the contact angle were performed at different points of time in order to analyze the changes of the wetting behavior of the specimens under ambient air conditions over time. For measures at each point of time, as well as each measurement direction (perpendicular and parallel), separate specimens were chosen to avoid distortion due to the residuals of previous measurements. Thus, altogether, 78 structures were manufactured and the wetting behavior of all surfaces was evaluated by employing the sessile drop method. All contact measurements were repeated three times and carried out with a defined drop volume of $5 \mu \mathrm{L}$ ultra-pure water with a defined dosage rate of $1 \mu \mathrm{L} / \mathrm{s}$ in atmospheric conditions. 
a syringe Injekt-F Solo 9166017V (B. Braun Melsungen AG, Melsungen, Germany) with a cannula Sterican ${ }^{\circledR}$ insulin G $27 \times 1 / 2$ " (B. Braun Melsungen AG, Melsungen, Germany) was used. a picture was taken $4 \mathrm{~s}$ after the drop was dispensed. By means of the video-based measuring system, the static contact angles (SCA) were determined by the software SCA20_U (Version 2, DataPhysics Instruments $\mathrm{GmbH}$, Filderstadt, Germany). For detailed imaging of the droplet wetting along the grooves, a light microscope of the type BX51 (Olympus, Hamburg, Germany) was used.

\section{Results and Discussion}

\subsection{Surface Topography of Laser-Treated Surfaces}

As shown in Figure 2, accurate trenches were fabricated and the structures exhibited clean material removal without burr formation. The shape of the trenches was highly reproducible, which is of key importance since burrs or similar heat damage could strongly influence the formation of the contact angle. The curved shape of the trenches was a result of the Gaussian power density distribution and repeated laser passages on the material. As can be observed in Figure $2 c, d$, a clear and pronounced formation of the commonly named femtosecond laser induced periodic structures (FLIPPS) in the gaps occurred through laser irradiation. FLIPPS are widely understood as interferences between linearly polarized laser light and excited surface plasmon polaritons [19]. FLIPPS are orientated perpendicular to the polarization vector of the incident light at fluences slightly higher than the ablation threshold. When considering the contact angle results, it must be noted that the struts with a width of $1 \mu \mathrm{m}$ feature FLIPPS on the top surface (see Figure 2a).
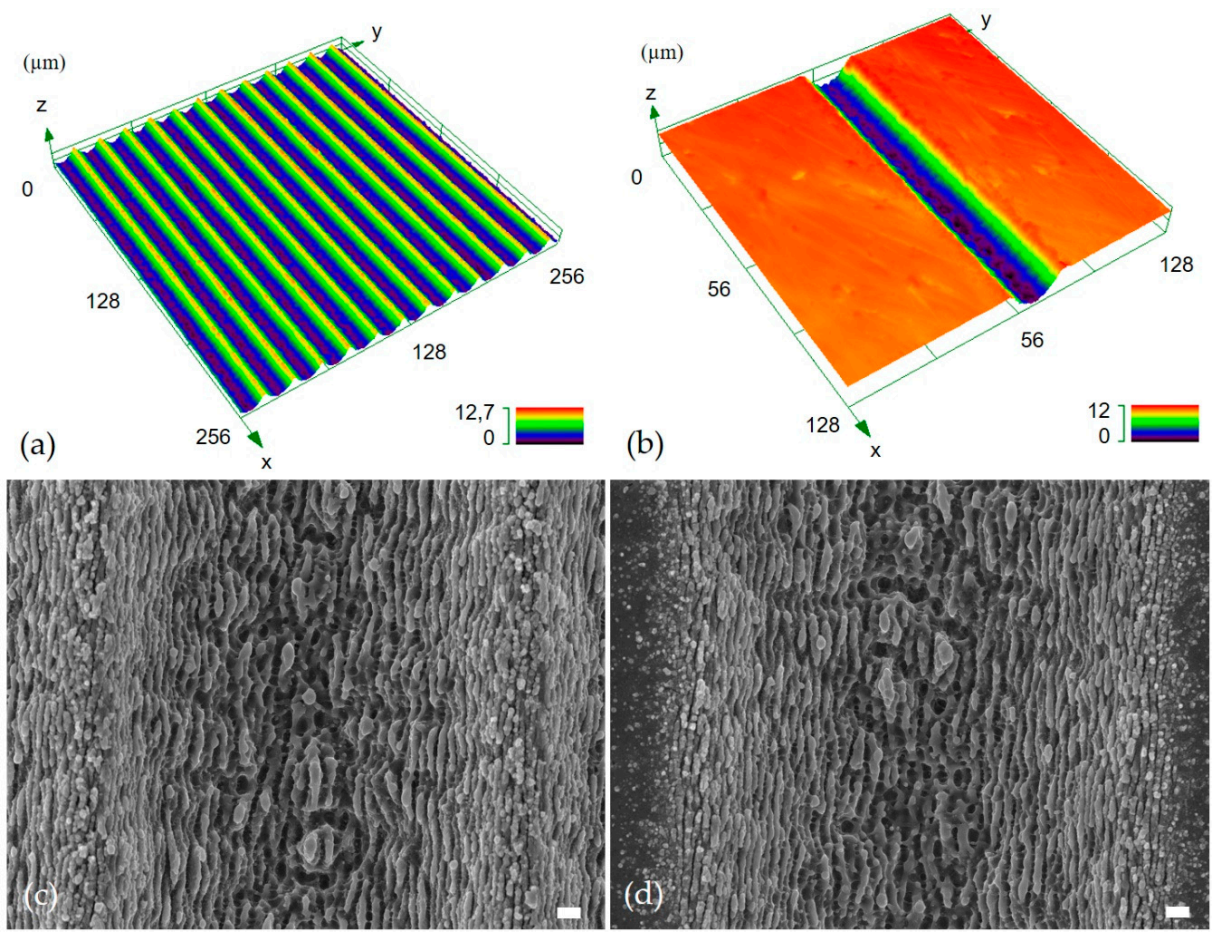

Figure 2. Surface topography after the laser process optimization. (a) CLSM image of deterministic structures with a strut width of $1 \mu \mathrm{m}$. (b) Detailed CLSM image of the gap profile with strut width of $300 \mu \mathrm{m}$. (c) SEM image of deterministic line structure with $1 \mu \mathrm{m}$ (scale bar $1 \mu \mathrm{m}$ ); the struts featuring FLIPPS on the top surface are arranged to the left and right sides of the picture. (d) SEM image of deterministic line structure with a $300-\mu \mathrm{m}$ strut width; sections of the strut surfaces can be seen to the left and right image border. FLIPPS can be observed on the entire surface of the grooves. 


\subsection{Contact Angle Measurements}

An evident anisotropic wetting behavior and contact angle increase over time was observed for all deterministic structures, as can be seen in Figures 3-5 The contact angles $\Theta_{\perp}$ in the perpendicular direction were always significantly lower than the contact angles $\Theta_{\|}$in the parallel direction. The strut width affected the resulting contact angle of the droplet. Strut widths from $1 \mu \mathrm{m}$ to $60 \mu \mathrm{m}$ led to lower contact angles than strut widths over $80 \mu \mathrm{m}$ in both directions after 1 day. Over time, the differences between contact angles at these strut widths became smaller. After one day, all contact angles were lower than the contact angle of the reference with $53.0^{\circ} \pm 1.9^{\circ}$. After 15 days, the parallel contact angles $\Theta_{\|}$were substantially higher than the reference with $54.6^{\circ} \pm 1.6^{\circ}$.

(a)

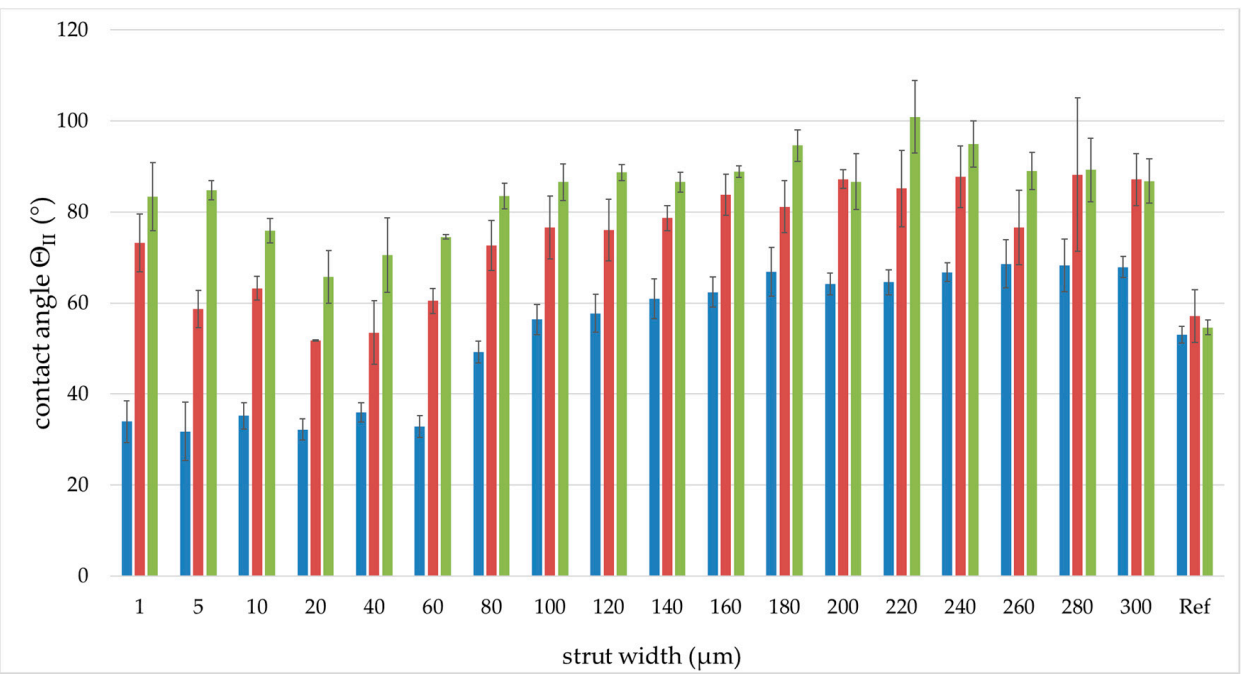

(b)

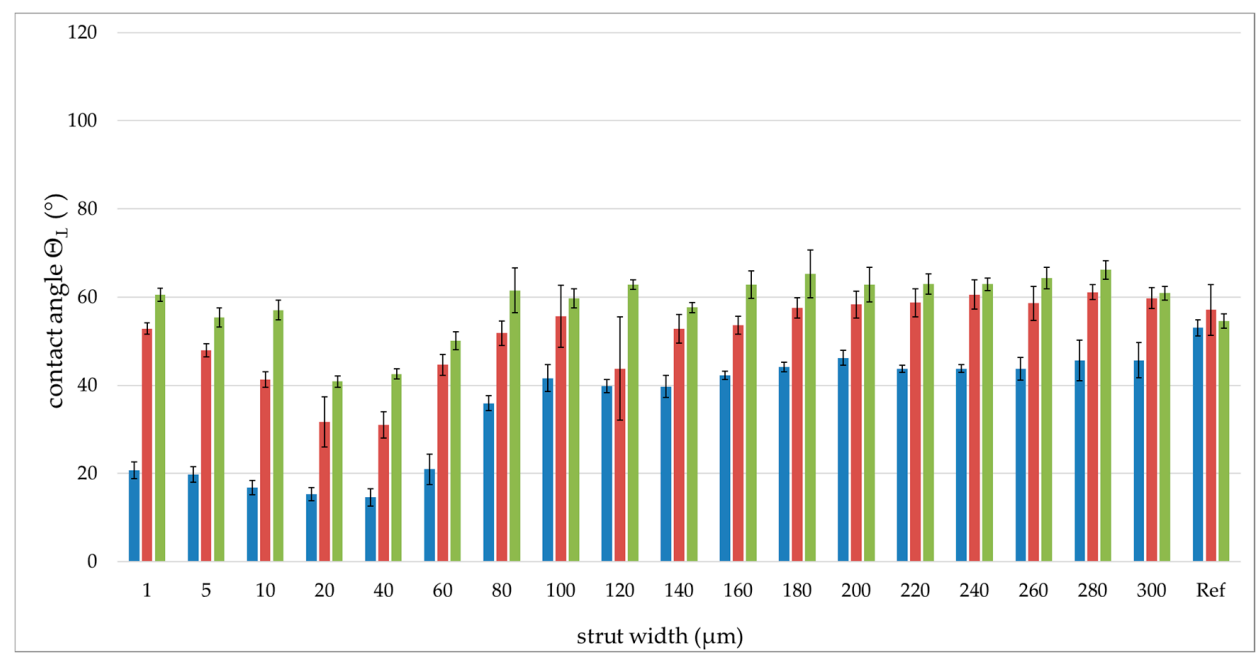

Figure 3. Contact angle over time (blue: 1 day, red: 8 days, and green: 15 days after laser treatment) and strut width. (a) Contact angles $\Theta_{\|}$parallel and (b) contact angles $\Theta_{\perp}$ perpendicular to the groove direction. 


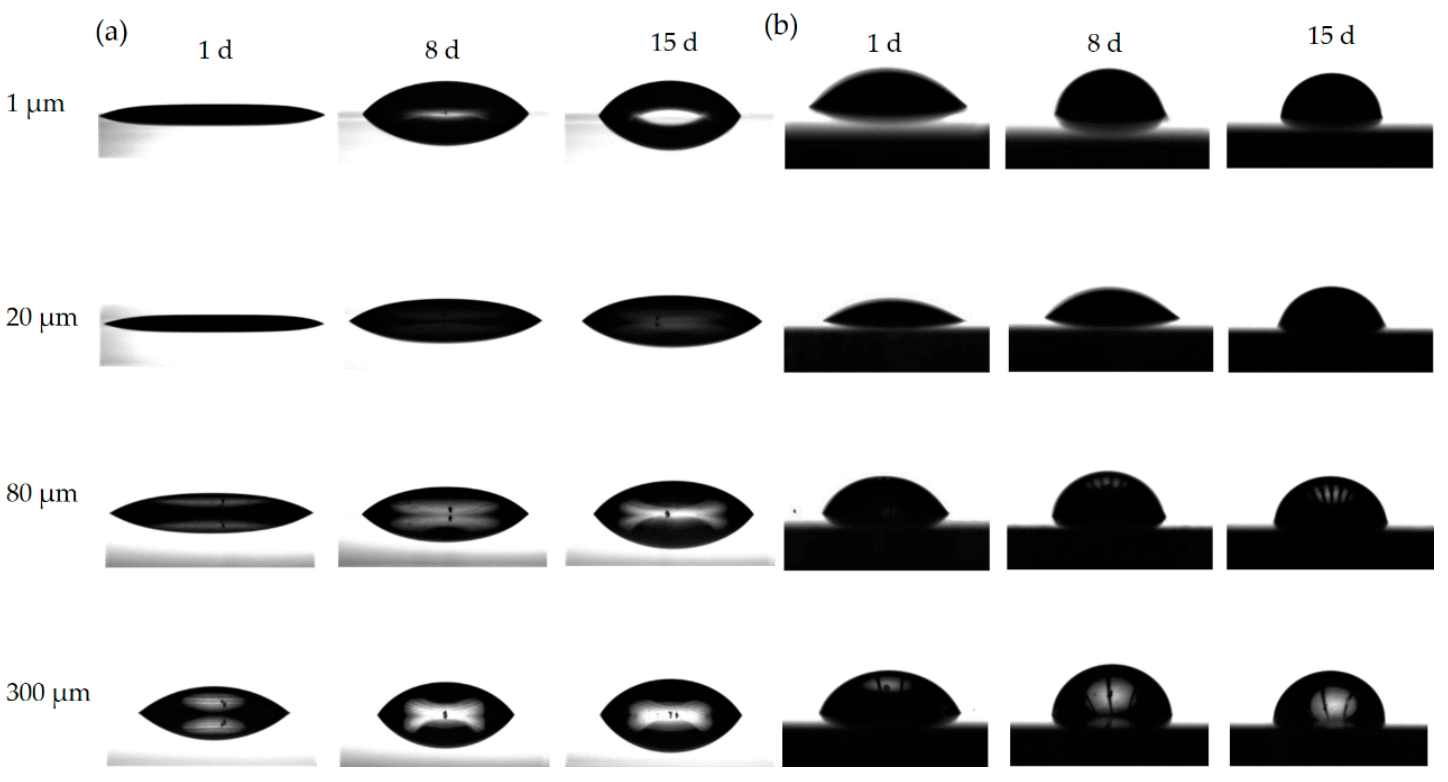

Figure 4. Selected image of the wetting state of structured surfaces over time with different strut widths. (a) Contact angles $\Theta_{\perp}$ in the perpendicular direction and (b) contact angles $\Theta_{\|}$in the parallel direction.
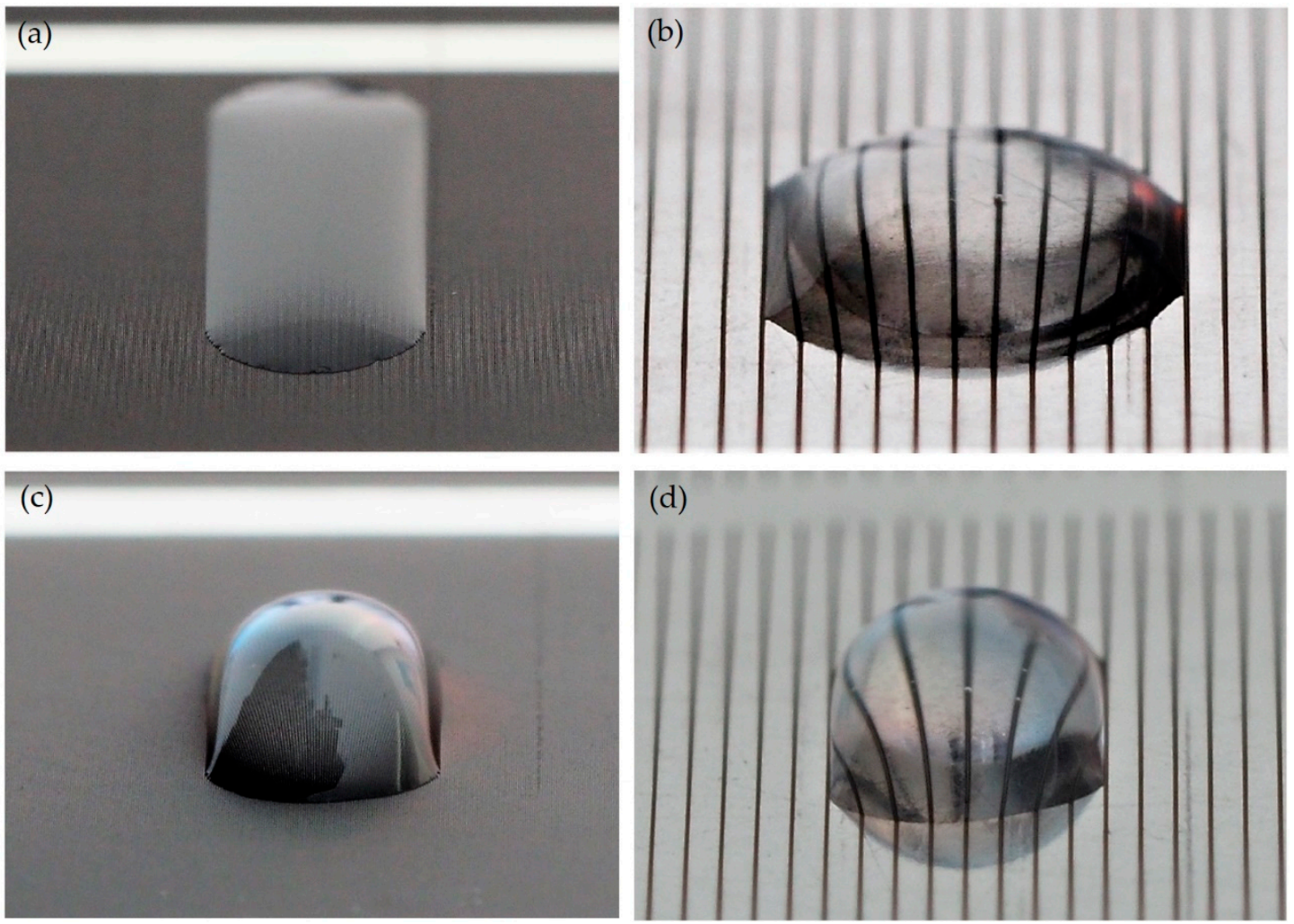

Figure 5. Selected images of droplet shape evolution on laser-structured surfaces over time. (a) Droplet shape after 1 day and (c) 15 days of storage on a deterministic line structure with a 1- $\mu \mathrm{m}$ strut width. (b) Droplet shape after 1 day and (d) 15 days of storage on a deterministic line structure with a 300- $\mu \mathrm{m}$ strut width.

Initially, all surfaces showed a hydrophilic behavior that could be particularly observed at narrow strut widths under $60 \mu \mathrm{m}$. The laser treatment immediately led to a change of the surface chemistry, which caused the hydrophilic behavior. Previous studies $[20,21]$ show that removal of low polar, organic molecules on the sample surface takes place due to the laser irradiation. Consequently, 
the carbon content decreases on the surface. The contaminations on the untreated surface consist of hydrocarbons from the ambient air. These contaminations cannot be removed by solvents, which was, for instance, shown on aluminum substrates [22]. Simultaneously, the laser treatment causes the formation of oxygenated groups and unsaturated $\mathrm{Al}^{3+}$ and $\mathrm{O}^{-}$elements that exhibit a high surface energy and high polarity, and act as Lewis acid and base sites. Consequently, the surface features highly hydrophilic behavior [20]. At narrow strut widths, the structured surface had a dominating impact on the wetting behavior, which led to an almost total wetting at the beginning, especially in the parallel direction along the grooves. This means that the capillary effect along the grooves dominated the wetting behavior. This effect could also clearly be seen in the pictures of the wetting state after 1 day in Figures 4 and 5a.

The hydrophilic behavior of the structured surfaces changed over time and the surfaces became increasingly hydrophobic. These changes were mainly dominated by the grooves since no significant changes of the wetting behavior could be found on the unstructured reference samples.

The change in wetting behavior of laser irradiated areas on metals is consistent with findings of other research groups and is related to a change in the chemical composition of the surface over time $[18,21,23,24]$. Several studies have been published with explanatory approaches for the changes. For instance, the absorption of organic molecules [16] or the decomposition of $\mathrm{CO}_{2}$ as an interaction between the surface and the ambient air [17], which leads to a deposition of nonpolar carbon or rather organic functional groups, are considered to be the cause of the changes of the chemical composition. The surface polarity strongly affects the affinity of a solid surface for water. a high polarity leads to high wettability and vice versa. It is presumed that the unsaturated elements $\left(\mathrm{Al}^{3+}\right)$ absorb hydroxyls from water molecules from the ambient air humidity over time. Thus, the Lewis acid pairs are reduced and the surface energy decreases within a short time after the laser treatment. Moreover, those functional hydroxyl groups represent the primary binding site for hydrocarbons, which are responsible for the strong change of the wettability over time due to their non-polar properties [16].

By consideration of the EDX mapping in Figure 6, it can be seen that the elements of oxygen and carbon occurred mainly in the laser-irradiated areas, while the principal elements of aluminum and titanium could be found in all areas. This perception coincides with the assumptions of the accumulation of carbon and oxide groups on irradiated areas, as described above. The process of absorption of carbon substrates and the increasing of the contact angles depends on the materials and amount of hydroxyl groups $\left(\mathrm{OH}^{-}\right)$on the surface [25], ambient atmosphere, storage conditions, and laser processing $[20,21]$.

The light microscope image in Figure $7 \mathrm{f}$ illustrates that no air was trapped in the gaps and total wetting occurred after 1 day of laser treatment. The slightly higher contact angles in the parallel direction can probably be explained by the pinning effect and a stronger deposit of oxygenated groups on the flanks, as seen in Figure 7. The portion of aluminum was slightly increased on the gap edges, which indicates, in conjunction with oxygen, the formation of alumina. The accumulation of hydrophilic alumina seemed to increase the pinning effect on the edges and could additionally hinder the spreading of the droplet in a perpendicular orientation, which led to higher contact angles $\Theta_{\|}$in the parallel direction. The light microscope image in Figure 7 also shows that the droplet was pinned at the edges, which lead to a stepwise progression of the water. The resulting drop with the graded shape was a result of the different distortion of the contact line in both directions and the energetic minimization of the surface-to-volume ratio and the total surface energy. An explanatory approach of the pinning effect on sharp structures with homogenous surfaces with edges of $90^{\circ}$ is given by the Gibbs inequality condition [26,27]. The structures in this study had smooth, rounded edges and the Gibbs condition was not valid. However, the droplet crossed the interruption induced by the struts in a perpendicular direction until an energetic equilibrium was reached. 

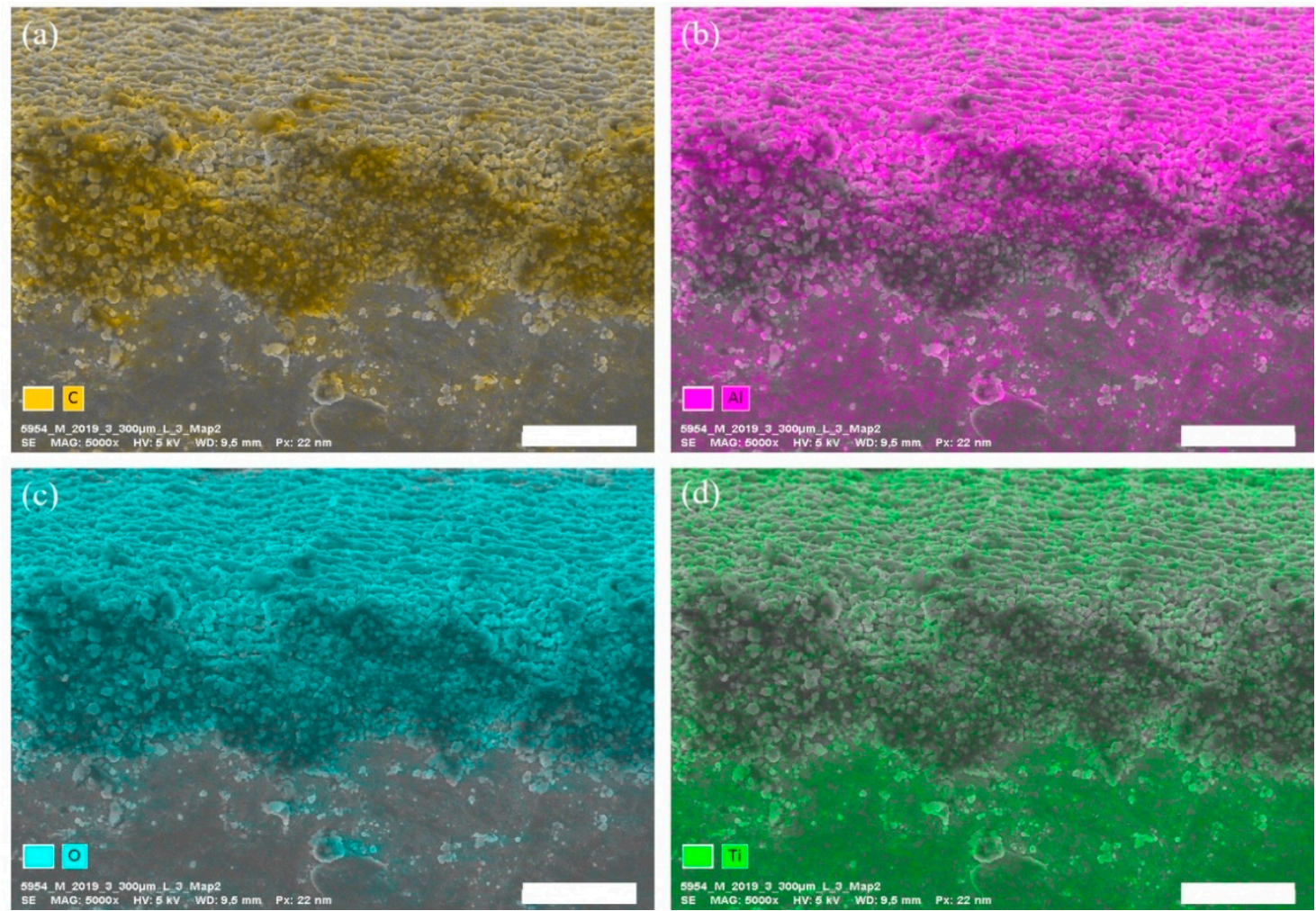

Figure 6. EDX mapping of the gap edges after 15 days of laser treatment with a $300-\mu \mathrm{m}$ strut width (scale bar: $3 \mu \mathrm{m}$ ). Mapping of (a) carbon, (b) aluminum, (c) oxygen, and (d) titanium.

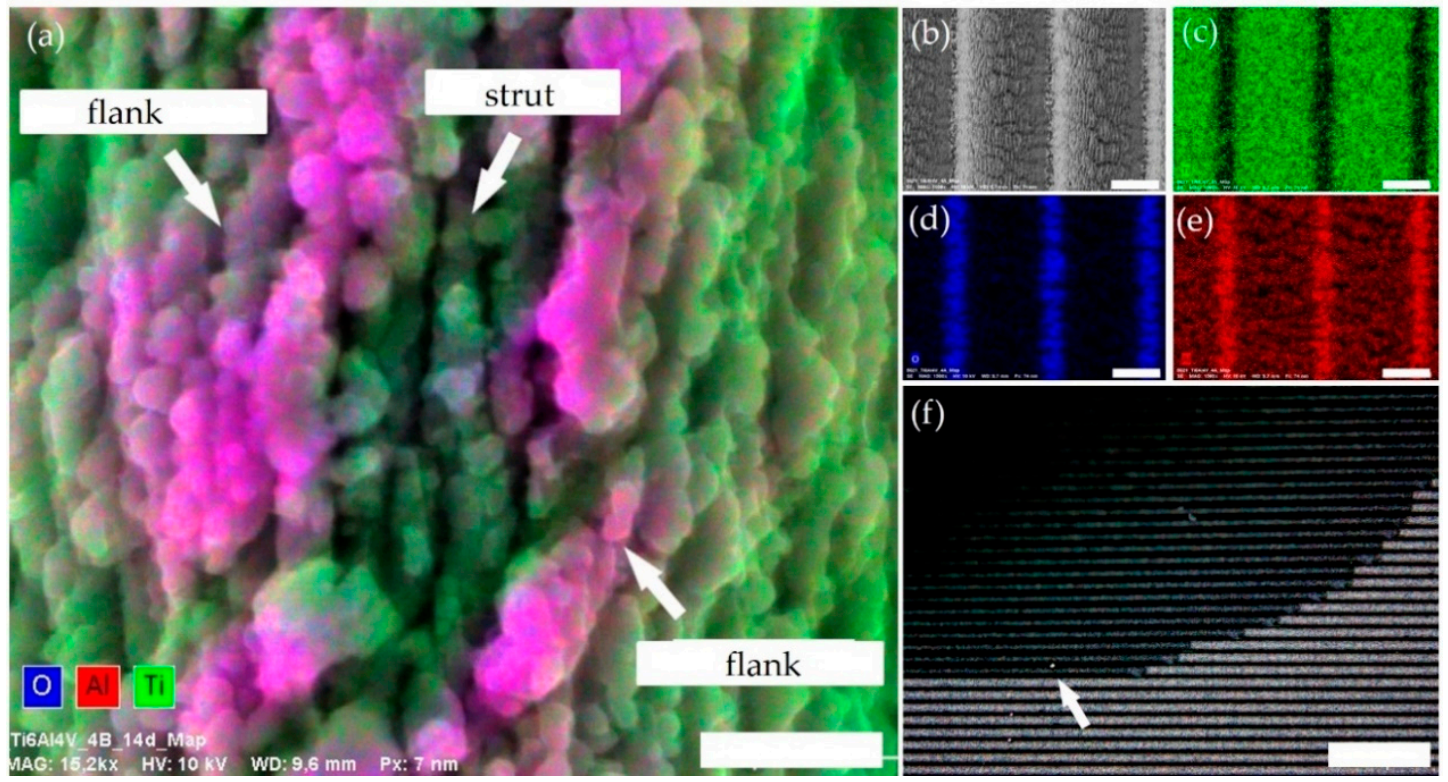

Figure 7. EDX mappings, SEM image, and microscope image of the deterministic structure with a 1- $\mu \mathrm{m}$ strut width 1 day after laser treatment: (a) composed element distribution of oxygen, aluminum, and titanium (scale bar $1 \mu \mathrm{m}$ ), (b) SEM image (scale bar $10 \mu \mathrm{m}$ ), (c) distribution of titanium (scale bar $10 \mu \mathrm{m}$ ), (d) distribution of oxygen (scale bar $10 \mu \mathrm{m}$ ), (e) distribution of aluminum (scale bar $10 \mu \mathrm{m}$ ), and (f) light microscope image (scale bar $20 \mu \mathrm{m}$ ) showing the stepwise progress of water on the surface.

The contact angles in both directions were different and anisotropic behavior was displayed at all measurement times. The largest anisotropic wetting value of the CA ratio of 2.47 and $\Delta \mathrm{CA}$ of 
$47.9^{\circ}$ at the $260-\mu \mathrm{m}$ strut width after 1 day was determined at a strut width of $40 \mu \mathrm{m}$. The advancing droplet along the grooves appeared to be steadily and more strongly hindered over time due to the increasing carbon or rather hydrophobic behavior within the structured grooves, which is observed in the left images in Figure 5a,c. Appropriate measurements are needed to confirm the increase of carbon, or rather carboxylates, that can only be measured insufficiently with EDX. X-ray photoelectron spectroscopy (XPS) should be used to further investigate this assumption. The maximum anisotropic contact angle value was determined with a CA ratio of 1.66 with a $40-\mu \mathrm{m}$ strut width and a $\triangle C A$ of $37.9^{\circ}$ with a $220-\mu \mathrm{m}$ strut width after 15 days of exposure to air. The lower drop shape anisotropy of the structures with higher CAs corresponds to the results of Neuhaus et al. [12]. Moreover, the exposure to air, or rather the surface chemistry change on laser microstructured areas, strongly affected the drop shape.

\section{Conclusions}

The present work shows that deterministically groove-structured Ti6Al4V surfaces using a femtosecond laser can feature a strong anisotropic wetting behavior. The resulting contact angles in the parallel and perpendicular directions were affected by the strut width. The generated anisotropic behavior also clearly depended on the surface chemistry within the gaps. The aspect ratio of the CAs in the parallel and perpendicular directions decreased with the increased hydrophobicity of the gaps.

Special attention regarding any further research should be drawn to the effect of different gap widths and gap depths on the wetting state, as well as on the influence of the laser machining on the microhardness. Moreover, further investigations should also focus on surface coatings or modifications, such as subsequent triboelectric polymer nanoparticle adhesion [28], that offer the ability to create solvent and chemical-treatment-free surfaces that finally lead to robust non-wetting surfaces with anisotropic properties.

Author Contributions: All authors conceived and designed the experiments. C.J. and G.S. manufactured the specimens and C.J. analyzed the surface properties and the wetting behavior. A.S. performed the EDX analysis and evaluated the data with the support of M.F. G.S. wrote the paper and H.S. reviewed and edited the paper.

Funding: This research was funded by the Federal Ministry of Education and Research (funding code: 03WKCU6B; Innovative Regional Growth Cores "MikroLas," which is part of the initiative "Entrepreneurial Regions"- "The BMBF Innovation Initiative for the New German Länder"). We also acknowledge financial support by the DFG and the University Rostock within the funding program Open Access Publishing.

Conflicts of Interest: The authors declare no conflict of interest. The funders had no role in the design of the study; in the collection, analyses, or interpretation of data; in the writing of the manuscript, or in the decision to publish the results.

\section{References}

1. Feng, L.; Li, S.; Li, Y.; Li, H.; Zhang, L.; Zhai, J.; Song, Y.; Liu, B.; Jiang, L.; Zhu, D. Super-Hydrophobic Surfaces: From Natural to Artificial. Adv. Mater. 2002, 14, 1857-1860. [CrossRef]

2. Zheng, Y.; Gao, X.; Jiang, L. (Directional adhesion of superhydrophobic butterfly wings. Soft Matter 2007, 3, 178-182. [CrossRef]

3. Xia, D.; He, X.; Jiang, Y.-B.; Lopez, G.P.; Brueck, S.R.J. Tailoring anisotropic wetting properties on submicrometer-scale periodic grooved surfaces. Langmuir 2010, 26, 2700-2706. [CrossRef]

4. Vorobyev, A.Y.; Guo, C. Multifunctional surfaces produced by femtosecond laser pulses. J. Appl. Phys. 2015, 117, 33103. [CrossRef]

5. Hwang, T.Y.; Vorobyev, A.Y.; Guo, C. Enhanced efficiency of solar-driven thermoelectric generator with femtosecond laser-textured metals. Opt. Express 2011, 19, A824-A829. [CrossRef] [PubMed]

6. Nayak, B.K.; Iyengar, V.V.; Gupta, M.C. Efficient light trapping in silicon solar cells by ultrafast-laser-induced self-assembled micro/nano structures. Prog. Photovolt. Res. Appl. 2011, 19, 631-639. [CrossRef]

7. Chung, J.Y.; Youngblood, J.P.; Stafford, C.M. Anisotropic wetting on tunable micro-wrinkled surfaces. Soft Matter 2007, 3, 1163. [CrossRef] 
8. Yoshimitsu, Z.; Nakajima, A.; Watanabe, T.; Hashimoto, K. Effects of Surface Structure on the Hydrophobicity and Sliding Behavior of Water Droplets. Langmuir 2002, 18, 5818-5822. [CrossRef]

9. Choi, W.; Tuteja, A.; Mabry, J.M.; Cohen, R.E.; McKinley, G.H. a modified Cassie-Baxter relationship to explain contact angle hysteresis and anisotropy on non-wetting textured surfaces. J. Colloid. Interface Sci. 2009, 339, 208-216. [CrossRef]

10. Lee, D.-K.; Choi, S.Y.; Park, M.S.; Cho, Y.H. Wetting properties of hybrid structure with hydrophilic ridges and hydrophobic channels. Appl. Phys. A 2018, 124, 308. [CrossRef]

11. Dorrer, C.; Rühe, J. Advancing and receding motion of droplets on ultrahydrophobic post surfaces. Langmuir 2006, 22, 7652-7657. [CrossRef] [PubMed]

12. Neuhaus, S.; Spencer, N.D.; Padeste, C. Anisotropic wetting of microstructured surfaces as a function of surface chemistry. ACS Appl. Mater. Interfaces 2012, 4, 123-130. [CrossRef] [PubMed]

13. Li, P.; Xie, J.; Cheng, J.; Wu, K.K. Anisotropic wetting properties on a precision-ground micro-V-grooved Si surface related to their micro-characterized variables. J. Micromech. Microeng. 2014, 24, 75004. [CrossRef]

14. Chen, F.; Zhang, D.; Yang, Q.; Wang, X.; Dai, B.; Li, X.; Hao, X.; Ding, Y.; Si, J.; Hou, X. Anisotropic wetting on microstrips surface fabricated by femtosecond laser. Langmuir 2011, 27, 359-365. [CrossRef]

15. Martínez-Calderon, M.; Rodríguez, A.; Dias-Ponte, A.; Morant-Miñana, M.C.; Gómez-Aranzadi, M.; Olaizola, S.M. Femtosecond laser fabrication of highly hydrophobic stainless steel surface with hierarchical structures fabricated by combining ordered microstructures and LIPSS. Appl. Surf. Sci. 2016, 374, 81-89. [CrossRef]

16. Long, J.; Zhong, M.; Zhang, H.; Fan, P. Superhydrophilicity to superhydrophobicity transition of picosecond laser microstructured aluminum in ambient air. J. Colloid. Interface Sci. 2015, 441, 1-9. [CrossRef]

17. Kietzig, A.-M.; Hatzikiriakos, S.G.; Englezos, P. Patterned superhydrophobic metallic surfaces. Langmuir 2009, 25, 4821-4827. [CrossRef]

18. Schnell, G.; Staehlke, S.; Duenow, U.; Nebe, J.B.; Seitz, H. Femtosecond Laser Nano/Micro Textured Ti6Al4V Surfaces-Effect on Wetting and MG-63 Cell Adhesion. Materials 2019, 12, 2210. [CrossRef]

19. Vorobyev, A.Y.; Guo, C. Direct femtosecond laser surface nano/microstructuring and its applications. Laser Photonics Rev. 2013, 7, 385-407. [CrossRef]

20. Jagdheesh, R.; Diaz, M.; Ocaña, J.L. Bio inspired self-cleaning ultrahydrophobic aluminium surface by laser processing. RSC Adv. 2016, 6, 72933-72941. [CrossRef]

21. Cardoso, J.T.; Garcia-Girón, A.; Romano, J.M.; Huerta-Murillo, D.; Jagdheesh, R.; Walker, M.; Dimov, S.S.; Ocaña, J.L. Influence of ambient conditions on the evolution of wettability properties of an IR-, ns-laser textured aluminium alloy. RSC Adv. 2017, 7, 39617-39627. [CrossRef]

22. van den Brand, J.; van Gils, S.; Beentjes, P.C.J.; Terryn, H.; Wit, J.H.W. Ageing of aluminium oxide surfaces and their subsequent reactivity towards bonding with organic functional groups. Appl. Surf. Sci. 2004, 235, 465-474. [CrossRef]

23. Bizi-Bandoki, P.; Benayoun, S.; Valette, S.; Beaugiraud, B.; Audouard, E. Modifications of roughness and wettability properties of metals induced by femtosecond laser treatment. Appl. Surf. Sci. 2011, 257, 5213-5218. [CrossRef]

24. Huerta-Murillo, D.; García-Girón, A.; Romano, J.M.; Cardoso, J.T.; Cordovilla, F.; Walker, M.; Dimov, S.S.; Ocaña, J.L. Wettability modification of laser-fabricated hierarchical surface structures in Ti-6Al-4V titanium alloy. Appl. Surf. Sci. 2019, 463, 838-846. [CrossRef]

25. Takeda, S.; Fukawa, M.; Hayashi, Y.; Matsumoto, K. Surface OH group governing adsorption properties of metal oxide films. Thin Solid Films 1999, 339, 220-224. [CrossRef]

26. Gibbs, J.W.; Wilson, E.B.; Page, T. The Scientific Papers of J. Willard Gibbs: Vol. I. Thermodynamics, Elementary Principles in Statistical Mechanics and Vector Analysis. Am. J. Phys. 1962, 30, 313-314. [CrossRef] 
27. Kusumaatmaja, H.; Vrancken, R.J.; Bastiaansen, C.W.M.; Yeomans, J.M. Anisotropic drop morphologies on corrugated surfaces. Langmuir 2008, 24, 7299-7308. [CrossRef] [PubMed]

28. Bayer, I.S.; Brandi, F.; Cingolani, R.; Athanassiou, A. Modification of wetting properties of laser-textured surfaces by depositing triboelectrically charged Teflon particles. Colloid. Polym. Sci. 2013, 291, 367-373. [CrossRef]

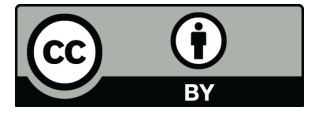

(C) 2019 by the authors. Licensee MDPI, Basel, Switzerland. This article is an open access article distributed under the terms and conditions of the Creative Commons Attribution (CC BY) license (http://creativecommons.org/licenses/by/4.0/). 